\title{
Respuesta productiva de gallinas a dietas con diferentes niveles de proteína
}

\author{
Performance of laying hens on diets with different levels of protein \\ B Fuente-Martínez ${ }^{\text {ab* }}$, GD Mendoza-Martínez ${ }^{\text {a }}$ J Arce-Menocalc ${ }^{\text {, C López-Coellod, E Avila-González }}$ \\ aDoctorado en Ciencias Biológicas, Universidad Autónoma Metropolitana Unidad Xochimilco, México D.F. \\ bentro de Enseñanza, Investigación y Extensión en Producción Avícola, Facultad de Medicina Veterinaria y Zootecnia, \\ Universidad Nacional Autónoma de México, México D.F. \\ 'Facultad de Medicina Veterinaria y Zootecnia, Universidad Michoacana de San Nicolás de Hidalgo, Michoacán, México. \\ ${ }^{\mathrm{d}}$ Departamento de Producción Animal, Aves, Facultad de Medicina Veterinaria y Zootecnia, \\ Universidad Nacional Autónoma de México, México D.F.
}

\begin{abstract}
SUMMARY
There is little information on the use of low-protein diets with the ideal protein profile for laying hen. An experiment was conducted to evaluate the layer performance of hen with low crude protein diets with the ideal protein profile. 240 hens Hy-Line W36 were used from 26 to 44 weeks of age, and the treatments were distributed among the experimental units in four treatments with five replicates of 12 birds each. The experimental design was completely random. The hens were fed sorghum plus soybean meal diets and synthetic amino acids formulated to $13,14,15$ and $16 \%$ crude protein with similar levels of digestible amino acids lysine $0.725 \%$ (100), $0.596 \%$ methionine and cystine (82), threonine $0.509 \%$ (70) and tryptophan $0.179 \%(25)$. The variables studied were feed intake, egg production, egg weight, egg mass per bird $\mathrm{d}^{-1}$ and feed conversion. An analysis of repeated observations and a regression analysis with quadratic transformation was determined with each level of crude protein. Furthermore, we calculated the value of protein to maximize performance using the derivative of the regression formula. There was a quadratic effect $(\mathrm{P} \leq 0.05)$ for egg production, egg weight, egg mass ave $\mathrm{d}^{-1}$ and feed consumption. The data analysis suggests that for better bird egg mass $\mathrm{d}^{-1}$ of laying hen Hy-Line W36, 15.3\% crude protein is required in the diet. The relationship lysine-arginine and lysine-valine could be limiting for diets with $13 \%$ crude protein.
\end{abstract}

Palabras clave: dietas bajas en proteína, gallina de postura, proteína ideal.

Key words: low protein diets, laying hen, ideal protein.

\section{INTRODUCCIÓN}

Un objetivo de la industria avícola es reducir el costo de alimentación que representa entre el 70 a $80 \%$ de los costos de producción de huevo. Las dietas deben ser adecuadas nutricionalmente, con un costo óptimo y reducir la eliminación de nitrógeno al ambiente. Roland (1980), Keshavarz y col (1980) y Calderon y Jensen (1990) presentan resultados variables del comportamiento productivo de la gallina de postura alimentada con dietas bajas en proteína, al mantener la producción de huevo y el peso promedio de huevo, mientras que Morris y Gous (1988) señalan un aumento en la producción y el peso del huevo al incrementar la proteína en la dieta. Gallinas alimentadas con dietas con 10,4\% de proteína cruda (PC), más lisina y metionina sintéticos mostraron una producción de huevo similar respecto a una dieta con $15,7 \%$ de PC (Johnson y Fisher 1958). Es similar la producción de huevo al alimentar aves con $12 \%$ de PC más aminoácidos comparando con dietas de 18\% de PC (Bray 1964). Keshavarz y Jackson

\footnotetext{
Aceptado: 01.09.2011.

* Salvador Díaz Mirón No 89, Col Zapotitlán, CP 12309, México DF, México; benjaminfuente@yahoo.com.mx
}

(1992) alimentaron gallinas de 22 a 66 semanas de edad con dietas con 15, 14, 13 y 12\% PC más metionina, lisina, triptófano e isoleucina, mostrando una disminución en la masa de huevo y el peso del ave respecto a aves alimentadas con $18 \%$ PC en la dieta. Se puede mantener la producción de huevo con dietas bajas en proteína con la adición de aminoácidos sintéticos, pero la masa de huevo se reduce en comparación con dietas altas en proteína (Penz y Jensen 1991). Summers y col (1991) reportan una reducción en la masa de huevo en un $11 \%$, en gallinas que consumieron una dieta con $10 \%$ PC más lisina, metionina, arginina y triptófano sintéticos, en relación con la dieta de 17\% PC.

Con la oferta de lisina, metionina, treonina y triptófano sintéticos, para optimizar la formulación es posible utilizar dietas con un menor contenido de proteína, sin embargo, la tendencia no solo es la de reducir la concentración de proteína, sino también que se elimine una menor cantidad de nitrógeno al ambiente (Harms y Russell 1993). Con formulación en base a aminoácidos digestibles indispensables para ofrecer de manera más precisa las necesidades para la síntesis de proteína y mantenimiento, es decir, sin tener deficiencias o excesos, las dietas se formulan a proteína ideal en base a un perfil de aminoácidos digestibles en relación a la lisina (Baker y Chung 1992). Con estos antecedentes, se realizó el presente estudio cuyo objetivo 
fue evaluar el comportamiento productivo de la gallina Hy-Line W36, al emplear dietas bajas en proteína y con los aminoácidos que se encuentran en forma comercial (L-lisina $\mathrm{HCl}$, DL-Metionina, L-Treonina y L-Triptófano) con el perfil de proteína ideal desarrollado en relación a lisina por Fuente y col (2005), y determinar si algún otro aminoácido esencial limita el comportamiento productivo de gallinas de postura alimentadas con dietas bajas en proteína.

\section{MATERIAL Y MÉTODOS}

La investigación se realizó en el Centro de Enseñanza, Investigación y Extensión en Producción Avícola (C.E.I.E.P.A.v) de la Facultad de Medicina Veterinaria y Zootecnia de la Universidad Nacional Autónoma de México, ubicado en la calle de Salvador Díaz Mirón N 89 en la Colonia Santiago Zapotitlán, Delegación Tlahuac, Distrito Federal, a una altura de $2.300 \mathrm{~m}, 19^{\circ} 15^{\prime} \mathrm{O}, 19^{\circ} 18^{\prime} \mathrm{N}$, 9902' O; clima templado húmedo $\mathrm{Cw}$, enero es el mes más frío y mayo el más caluroso, temperatura promedio anual de $16{ }^{\circ} \mathrm{C}$ y precipitación pluvial anual media de $747 \mathrm{~mm}$. Se usó en una caseta de ambiente natural y las aves fueron alojadas en jaulas tipo California de dos niveles de $40 \mathrm{~cm} \times 46 \mathrm{~cm}$ cada jaula. Se usaron 240 aves de 26 semanas de edad y 8 semanas en producción Hy-Line W36 con un peso promedio de $1.501 \mathrm{~g}$. Los cuatro tratamientos se distribuyeron entre las unidades experimentales con cinco réplicas de 12 aves cada una (tres aves por jaula); el diseño experimental fue completamente al azar. Las gallinas se alimentaron con dietas (cuadro 1) sorgo + pasta de soya, formuladas a $13,14,15$ y $16 \%$ de proteína cruda con niveles similares de los aminoácidos más limitantes y conservando la misma relación de aminoácidos con respecto a la lisina digestible (lisina\% 0,725 (100), aminoácidos azufrados\% $0,596(82)$, treonina\% 0,509 (70) y triptófano\% 0,179 (25)) en forma digestible y $2.900 \mathrm{kcal}^{-1} \mathrm{~kg}$ EM. Se analizó el contenido de proteína cruda en el sorgo y pasta de soya mediante la técnica que marca el AOAC (Method 976.05, 2002) y se realizó la determinación de aminoácidos en los ingredientes mediante la técnica de NIR (Reeves 2000). Los coeficientes de la digestibilidad de los aminoácidos para los ingredientes, son los publicados por Cuca y col (2008) y la relación de aminoácidos es la reportada por Fuente y col (2005).

En la caseta donde se alojaron las aves, la luz natural fue complementada con luz artificial para contar con un fotoperiodo de $16 \mathrm{~h}$. El alimento y el agua se proporcionaron a libre acceso durante las 18 semanas del experimento. Diariamente se recogió el huevo a las 11:00 h, se contabilizó, se pesó y se resumieron semanalmente los datos de consumo de alimento, porcentaje de postura, peso promedio del huevo, masa de huevo por ave $\mathrm{d}^{-1}$ (\% de postura por peso del huevo en $\mathrm{g} / \mathrm{100})$ y conversión alimentaria ( $\mathrm{kg}$ de huevo / consumo de alimento $\mathrm{kg}$ ). Adicionalmente se calculó el consumo de lisina, aminoácidos azufrados, treonina, triptófano y arginina con cada dieta.

Para el análisis de los datos obtenidos se utilizó SPSS ver 8.0 para Windows (SPSS Inc, Chicago IL, USA 1989) para un análisis de observaciones repetidas; y un análisis de regresión con transformación cuadrática con cada nivel de proteína. Al encontrarse una relación entre las variables productivas y los niveles de proteína, se calculó un máximo o un mínimo por medio de su derivada igualándola a cero (Denis 1987). Los resultados para cada variable se presentan como media \pm error estándar de la media y la comparación de las mismas se realizó mediante la prueba de Tukey.

\section{RESULTADOS}

Los resultados promedio obtenidos en 18 semanas de experimentación en las variables de porcentaje de postura, peso del huevo, masa de huevo, consumo de alimento y conversión alimentaria aparecen en el cuadro 2, no se encontró efecto con los diferentes niveles de proteína ( $\mathrm{P}>0,05)$, ni interacción entre el tiempo y los niveles de proteína usados $(\mathrm{P}>0,05)$, por lo que se interpretó el efecto del tiempo. Para porcentaje de postura se encontró un efecto cuadrático; por cada semana de producción que pasa el porcentaje de postura disminuye en promedio $0,6 \%$ semanal, el cual es explicado por la ecuación para \% de postura $\mathrm{Y}=94,7-0,58 *$ semana $-0,01 *(\text { semana }-9,5)^{1 / 2}$ con una $\mathrm{R}^{2}=0,40(\mathrm{P} \leq 0,001)$; el peso del huevo se incrementó de $53 \mathrm{~g}$ hasta $62,4 \mathrm{~g}$, teniendo incrementos semanales en promedio de $0,04 \mathrm{~g}$ explicado por la siguiente ecuación del peso promedio del huevo $\mathrm{g}: \mathrm{Y}=54,5+0,49 *$ semana $-0,01 *(\text { semana }-9,5)^{1 / 2} \mathrm{R}^{2}=0,86(\mathrm{P} \leq 0,001)$. Para la masa de huevo ave $\mathrm{d}^{-1}$, también se incrementó de 48,6 g hasta $52,5 \mathrm{~g}$, influyendo en esta variable fuertemente el porcentaje de postura más que el peso del huevo para el tipo de respuesta cúbica con la ecuación de masa de huevo ave $\mathrm{d}^{-1} \mathrm{~g} \mathrm{Y}=54,2-0,14 *$ semana $-0,02 *(\text { semana }-9,5)^{1 / 2}$ $+0,005 *(\text { semana }-9,5)^{3 / 4} \mathrm{R}^{2}=0,13(\mathrm{P} \leq 0,001)$. Para consumo de alimento y conversión alimentaria también se encontró un efecto cuadrático con $\mathrm{R}^{2}=0,09 ; 0,04$ las cuales se consideraron muy bajas.

En el cuadro 3 se muestran los resultados promedio de los cuatro tratamientos para las variables de porcentaje de postura, peso del huevo, masa de huevo ave $\mathrm{d}^{-1}$, consumo de alimento ave $\mathrm{d}^{-1}$ y conversión alimentaria. Se aprecia que sólo la dieta que contenía 13\% PC obtuvo los menores valores productivos para porcentaje de postura, peso del huevo y masa de huevo ave $\mathrm{d}^{-1}$, con respecto a las dietas que contenían 14,15 y $16 \% \mathrm{PC}(\mathrm{P} \leq 0,001)$. El consumo de alimento fue mayor en la dieta de $14 \%$ proteína con respecto a los otros niveles de proteína cruda $(13,15 \mathrm{y}$ $16 \%$ ) y la conversión alimentaria fue mayor para los tratamientos con 13 y $14 \% \mathrm{PC}$, con respecto a los tratamientos que contenían 15 y $16 \% \mathrm{PC}(\mathrm{P} \leq 0,001)$. 
Cuadro 1. Composición y aporte nutricional de las dietas experimentales.

Experimental diets composition and nutritional content.

\begin{tabular}{|c|c|c|c|c|c|}
\hline \multirow{2}{*}{ Ingredientes $\left(\mathrm{kg} \mathrm{t}^{-1}\right)$} & & \multicolumn{4}{|c|}{ \% de proteína cruda en la dieta } \\
\hline & & 13 & 14 & 15 & 16 \\
\hline Sorgo & & 716,049 & 688,579 & 661,106 & 633,624 \\
\hline Pasta de soya & & 137,45 & 163,669 & 189,889 & 216,111 \\
\hline Carbonato de calcio & & 92,606 & 92,555 & 92,504 & 92,453 \\
\hline Aceite vegetal & & 23,892 & 26,887 & 29,881 & 32,879 \\
\hline Fosfato de calcio & & 15,095 & 14,972 & 14,850 & 14,727 \\
\hline Sal & & 3,639 & 3,632 & 3,626 & 3,619 \\
\hline Vitaminas y minerales $^{\dagger}$ & & 2,500 & 2,500 & 2,500 & 2,500 \\
\hline DL-metionina (99\%) & & 2,462 & 2,231 & 2,00 & 1,769 \\
\hline Pigmentos vegetal amarillo y rojo ${ }^{\dagger \dagger}$ & & 1,030 & 1,030 & 1,030 & 1,030 \\
\hline Cloruro de colina $60 \%$ & & 0,500 & 0,500 & 0,500 & 0,500 \\
\hline L-lisina $\mathrm{HCl}(78,8 \%)$ & & 2,958 & 2,134 & 1,311 & 0,488 \\
\hline Bacitracina de zinc & & 0,150 & 0,150 & 0,150 & 0,150 \\
\hline Antioxidante & & 0,150 & 0,150 & 0,150 & 0,150 \\
\hline L-treonina $(98,5 \%)$ & & 1,116 & 0,743 & 0,370 & 0,000 \\
\hline L-triptófano $(99,0 \%)$ & & 0,403 & 0,268 & 0,133 & 0,000 \\
\hline Total & & 1.000 & 1.000 & 1.000 & 1.000 \\
\hline \multicolumn{6}{|c|}{ Análisis calculado } \\
\hline Energía metabolizable & $\left(\mathrm{Kcal}^{-1} \mathrm{~kg}\right)$ & 2.900 & 2.900 & 2.900 & 2.900 \\
\hline Proteína cruda & $(\%)$ & 13 & 14 & 15 & 16 \\
\hline Lisina digestible & $(\%)$ & 0,725 & 0,725 & 0,725 & 0,725 \\
\hline Metionina digestible & $(\%)$ & 0,419 & 0,408 & 0,397 & 0,387 \\
\hline Metionina+cistina digestible & $(\%)$ & 0,596 & 0,596 & 0,596 & 0,596 \\
\hline Treonina digestible & $(\%)$ & 0,509 & 0,509 & 0,509 & 0,509 \\
\hline Triptófano digestible & $(\%)$ & 0,179 & 0,179 & 0,179 & 0,179 \\
\hline Arginina digestible & $(\%)$ & 0,673 & 0,751 & 0,829 & 0,907 \\
\hline Valina digestible & $(\%)$ & 0,571 & 0,616 & 0,660 & 0,705 \\
\hline Leucina digestible & $(\%)$ & 1,259 & 1,318 & 1,376 & 1,434 \\
\hline Isoleucina digestible & $(\%)$ & 0,518 & 0,563 & 0,607 & 0,652 \\
\hline Calcio total & $(\%)$ & 3,700 & 3,700 & 3,700 & 3,700 \\
\hline Fósforo disponible & $(\%)$ & 0,400 & 0,400 & 0,400 & 0,400 \\
\hline Sodio & $(\%)$ & 0,150 & 0,150 & 0,150 & 0,150 \\
\hline Acido linoleico & $(\%)$ & 2,059 & 2,188 & 2,317 & 2,446 \\
\hline Grasa cruda & $(\%)$ & 4,603 & 4,849 & 5,095 & 5,342 \\
\hline
\end{tabular}

$\dagger \quad$ Premezcla de vitaminas y minerales por kg: vitamina A 3, 574, $400 \mathrm{UI}$; vitamina $\mathrm{D}_{3} 1,344,000 \mathrm{UI}$; vitamina E 3, 216 UI; vitamina $\mathrm{K}_{3} 1.112 \mathrm{~g}$; riboflavina $2.228 \mathrm{~g}$; niacina $8.960 \mathrm{~g}$; ácido pantoténico $5.592 \mathrm{~g}$; cianocobalamina $0,004 \mathrm{~g}$; colina $106 \mathrm{~g}$; antioxidante $0.016 \mathrm{~g}$; cobalto $0,040 \mathrm{~g}$; hierro $12 \mathrm{~g}$; yodo $0,040 \mathrm{~g}$; manganeso $24 \mathrm{~g}$; zinc $14 \mathrm{~g}$; selenio $0,040 \mathrm{~g}$; cobre $0,6 \mathrm{~g}$; excipiente c b p $1000 \mathrm{~g}$.

i† $15 \mathrm{~g}$ carotenoides amarillos y $5 \mathrm{~g}$ de carotenoides rojos (Pigmentos Vegetales del Centro S.A. de C.V. Celaya Guanajuato México).

Al calcular el consumo de los aminoácidos (cuadro 4) por tratamiento, se encontró que con la dieta de $14 \%$ de proteína cruda se tenía el mayor consumo de lisina, aminoácidos azufrados, treonina y triptófano $(\mathrm{P} \leq 0,001)$. El tratamiento con $16 \%$ PC tuvo el mayor consumo de arginina y de proteína con respecto a los otros tratamientos (13, 14 y $15 \%$ PC). La relación de aminoácidos (met + cist, treonina y triptófano), en todos los tratamientos con respecto a la lisina (considerándola como 100\%), fue similar al que Fuente y col (2005) habían reportado a excepción de la relación de lisina:arginina (cuadro 5), la cual en la dieta con 13\% PC fue la menor relación con respecto a la lisina $(92,8 \%)$ y esta se incrementó conforme se aumentó el nivel de proteína.

El análisis de los resultados de la regresión polinomial para las variables productivas (\% de postura, peso del huevo, masa de huevo y conversión alimentaria) con respecto a los diferentes niveles de proteína indica un efecto cuadrático 
B FUENTE-MARTÍNEZ Y COL

Cuadro 2. Respuesta al tiempo de las variables productivas.

Time performance of productive traits.

\begin{tabular}{|c|c|c|c|c|c|}
\hline Semana & $\begin{array}{c}\% \\
\text { de } \\
\text { postura }\end{array}$ & $\begin{array}{c}\text { Peso } \\
\text { del } \\
\text { huevo, g }\end{array}$ & $\begin{array}{l}\text { Masa de } \\
\text { huevo, } \\
\text { ave } \mathrm{d}^{-1} \mathrm{~g}^{-1}\end{array}$ & $\begin{array}{l}\text { Consumo de } \\
\text { alimento, } \\
\text { ave } \mathrm{d}^{-1} \mathrm{~g}\end{array}$ & $\begin{array}{c}\text { Conversión } \\
\text { alimentaria } \\
\mathrm{kg}: \mathrm{kg}\end{array}$ \\
\hline 1 & 90,7 & 53,5 & 48,6 & 96 & 1,987 \\
\hline 2 & 93,3 & 54,5 & 50,9 & 94 & 1,853 \\
\hline 3 & 92,3 & 55,4 & 51,2 & 97 & 1,898 \\
\hline 4 & 92,5 & 56,5 & 52,3 & 97 & 1,861 \\
\hline 5 & 92,2 & 56,9 & 52,5 & 100 & 1,897 \\
\hline 6 & 91,8 & 57,1 & 52,5 & 98 & 1,867 \\
\hline 7 & 90,7 & 57,8 & 52,5 & 103 & 1,965 \\
\hline 8 & 89,5 & 58,4 & 52,3 & 97 & 1,859 \\
\hline 9 & 89,3 & 59,1 & 52,8 & 99 & 1,871 \\
\hline 10 & 89,2 & 59,4 & 53,0 & 98 & 1,844 \\
\hline 11 & 88,7 & 60,0 & 53,2 & 99 & 1,863 \\
\hline 12 & 87,8 & 60,5 & 53,1 & 100 & 1,879 \\
\hline 13 & 86,3 & 60,9 & 52,5 & 99 & 1,882 \\
\hline 14 & 83,4 & 60,9 & 50,8 & 95 & 1,875 \\
\hline 15 & 81,7 & 61,6 & 50,4 & 103 & 2,058 \\
\hline 16 & 85,3 & 61,8 & 52,8 & 98 & 1,867 \\
\hline 17 & 84,0 & 61,9 & 52,0 & 99 & 1,917 \\
\hline 18 & 84,1 & 62,5 & 52,5 & 101 & 1,936 \\
\hline Promedio & 88,5 & 58,8 & 51,99 & 98,4 & 1,898 \\
\hline EEM & 0,84 & 0,22 & 0,57 & 0,63 & 0,019 \\
\hline Ecuación & $\begin{array}{c}94,7-0,58 * \\
\text { semana }-0,01 * \\
(\text { semana- } 9,5)^{1 / 2}\end{array}$ & $\begin{array}{c}54,5+0,49 * \\
\text { semana }-0,01 * \\
(\text { semana- } 9,5)^{1 / 2}\end{array}$ & $\begin{array}{c}54,2-0,14 * \\
\text { semana }-0,02 * \\
(\text { semana- } 9,5)^{1 / 2} \\
+0,005 * \\
(\text { semana- } 9,5)^{3 / 4}\end{array}$ & $\begin{array}{c}96,9+0,2^{*} \\
\text { semana }-0,01 * \\
(\text { semana- } 9,5)^{1 / 2}\end{array}$ & $\begin{array}{c}1,862+0,001 * \\
\text { semana }+0,001 * \\
(\text { semana- } 9,5)^{1 / 2}\end{array}$ \\
\hline $\mathrm{R}^{2}$ & 0,40 & 0,86 & 0,13 & 0,09 & 0,04 \\
\hline$P \leq$ & 0,001 & 0,001 & 0,001 & 0,001 & 0,001 \\
\hline
\end{tabular}

$\mathrm{EE}=$ error estándar.

Cuadro 3. Resultados promedio en 18 semanas de las variables productivas. Average results of 18 weeks of the production traits.

\begin{tabular}{lccccc}
\hline \multirow{2}{*}{ Variable } & \multicolumn{5}{c}{ Nivel de proteína } \\
\cline { 2 - 6 } & $13 \%$ & $14 \%$ & $15 \%$ & $16 \%$ & EE \\
\hline \% de postura & $86,8^{\mathrm{b}}$ & $88,7^{\mathrm{a}}$ & $89,3^{\mathrm{a}}$ & $89,2^{\mathrm{a}}$ & 0,39 \\
Peso del huevo, g & $58,1^{\mathrm{b}}$ & $58,8^{\mathrm{a}}$ & $59,0^{\mathrm{a}}$ & $59,1^{\mathrm{a}}$ & 0,10 \\
Masa de huevo, ave $\mathrm{d}^{-1} \mathrm{~g}^{-1}$ & $50,4^{\mathrm{b}}$ & $52,1^{\mathrm{a}}$ & $52,6^{\mathrm{a}}$ & $52,6^{\mathrm{a}}$ & 0,26 \\
Consumo de alimento, ave d ${ }^{-1} \mathrm{~g}$ & $97,6^{\mathrm{b}}$ & $99,9^{\mathrm{a}}$ & $98,3^{\mathrm{b}}$ & $97,6^{\mathrm{b}}$ & 0,30 \\
Conversión alimentaria & $1,945^{\mathrm{a}}$ & $1,920^{\mathrm{a}}$ & $1,871^{\mathrm{b}}$ & $1,857^{\mathrm{b}}$ & 0,009 \\
\hline
\end{tabular}

Valores con diferente letra en fila son distintos $(\mathrm{P} \leq 0,001)$.

$\mathrm{EE}=$ error estándar. 
Cuadro 4. Consumo diario de aminoácidos y de proteína cruda en gallinas.

Daily feed intake of crude protein and amino acids in laying hens.

\begin{tabular}{|c|c|c|c|c|c|}
\hline \multirow{2}{*}{ Consumo } & \multicolumn{4}{|c|}{ Nivel de proteína cruda $\%$} & \multirow[b]{2}{*}{$\mathrm{EE}$} \\
\hline & 13 & 14 & 15 & 16 & \\
\hline Lisina, mg & $710^{\mathrm{b}}$ & $725^{\mathrm{a}}$ & $713^{\mathrm{b}}$ & $708^{b}$ & 2,2 \\
\hline Azufrados, mg & $584^{\mathrm{b}}$ & $596^{\mathrm{a}}$ & $586^{\mathrm{b}}$ & $582^{\mathrm{b}}$ & 1,8 \\
\hline Treonina, mg & $498^{\mathrm{b}}$ & $509^{\mathrm{a}}$ & $501^{\mathrm{b}}$ & $497^{\mathrm{b}}$ & 1,5 \\
\hline Triptófano, mg & $175^{\mathrm{b}}$ & $179^{\mathrm{a}}$ & $176^{\mathrm{b}}$ & $175^{\mathrm{b}}$ & 0,5 \\
\hline Arginina, mg & $659^{\mathrm{d}}$ & $751^{\mathrm{c}}$ & $816^{\mathrm{b}}$ & $886^{\mathrm{a}}$ & 2,4 \\
\hline Valina, mg & $559^{\mathrm{d}}$ & $616^{\mathrm{c}}$ & $649^{\mathrm{b}}$ & $689^{a}$ & 1,9 \\
\hline Leucina, mg & $1.233^{\mathrm{d}}$ & $1.318^{\mathrm{c}}$ & $1.354^{\mathrm{b}}$ & $1.401^{\mathrm{a}}$ & 4,2 \\
\hline Isoleucina, $\mathrm{mg}$ & $507^{\mathrm{d}}$ & $563^{\mathrm{c}}$ & $597^{\mathrm{b}}$ & $637^{\mathrm{a}}$ & 1,8 \\
\hline Proteína, g & $12,73^{\mathrm{d}}$ & $14,00^{\mathrm{c}}$ & $14,76^{\mathrm{b}}$ & $15,63^{\mathrm{a}}$ & 0,04 \\
\hline
\end{tabular}

a, b, c, d Valores con distinta literal en fila son estadísticamente diferentes $(\mathrm{P} \leq 0,001)$.

$\mathrm{EE}=$ error estándar.

Cuadro 5. Relación de aminoácidos (\%) para la gallina de postura con el concepto de proteína ideal. Amino acid ratio (\%) for laying hen with the concept of ideal protein.

\begin{tabular}{lcccc}
\hline \multirow{2}{*}{ Aminoácido } & \multicolumn{4}{c}{ Nivel de proteína cruda \% } \\
\cline { 2 - 5 } & 13 & 14 & 15 & 16 \\
\hline Lisina & 100 & 100 & 100 & 100 \\
Azufrados & 82,3 & 82,2 & 82,2 & 82,2 \\
Treonina & 70,1 & 70,2 & 70,3 & 70,2 \\
Triptófano & 24,7 & 24,7 & 24,7 & 24,7 \\
Arginina & 92,8 & 103,6 & 114,4 & 125,1 \\
Valina & 78,7 & 84,9 & 91,0 & 97,3 \\
Leucina & 1,73 & 1,81 & 1,89 & 1,98 \\
Isoleucina & 71,4 & 77,6 & 83,7 & 89,9 \\
\hline
\end{tabular}

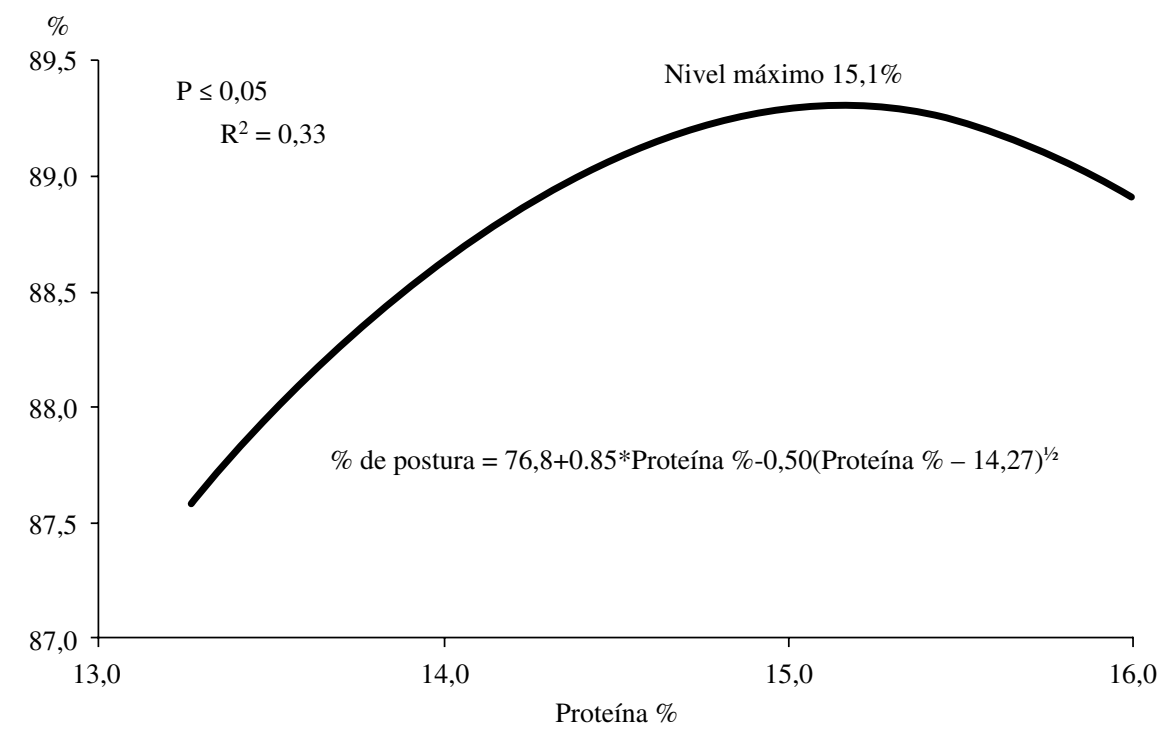

Figura 1. Respuesta a porcentaje de postura en gallinas con diferentes niveles de proteína. Response to egg production in laying hens fed with different protein levels. 


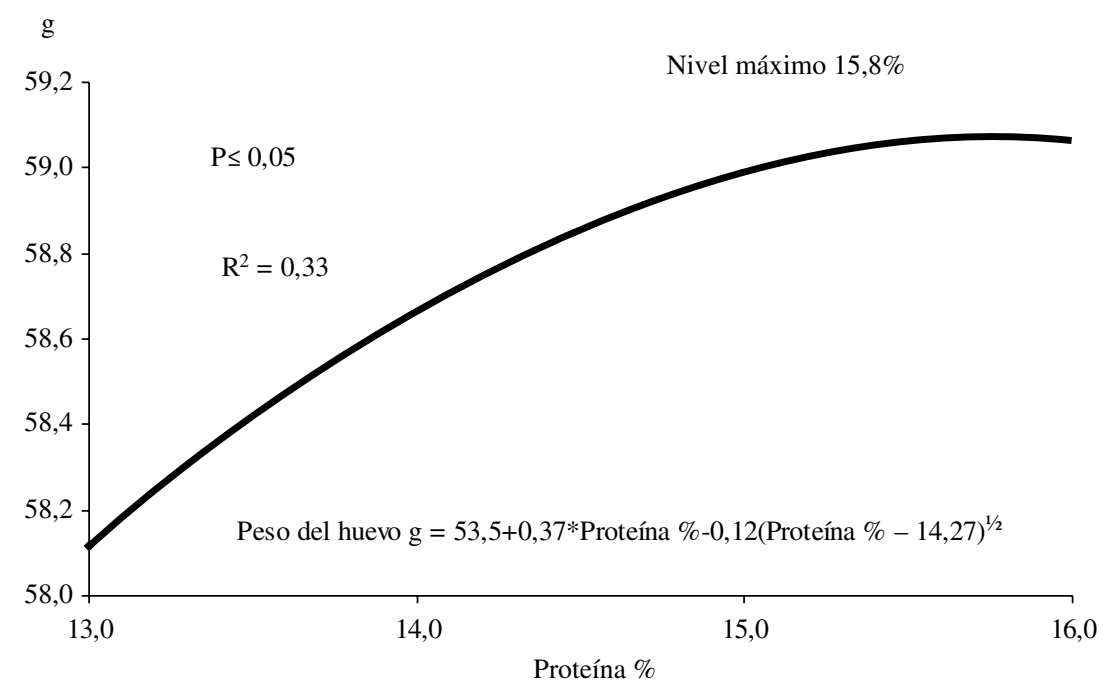

Figura 2. Respuesta del peso del huevo en gallinas con diferentes niveles de proteína. Response of egg weight in laying hens fed with different protein levels.

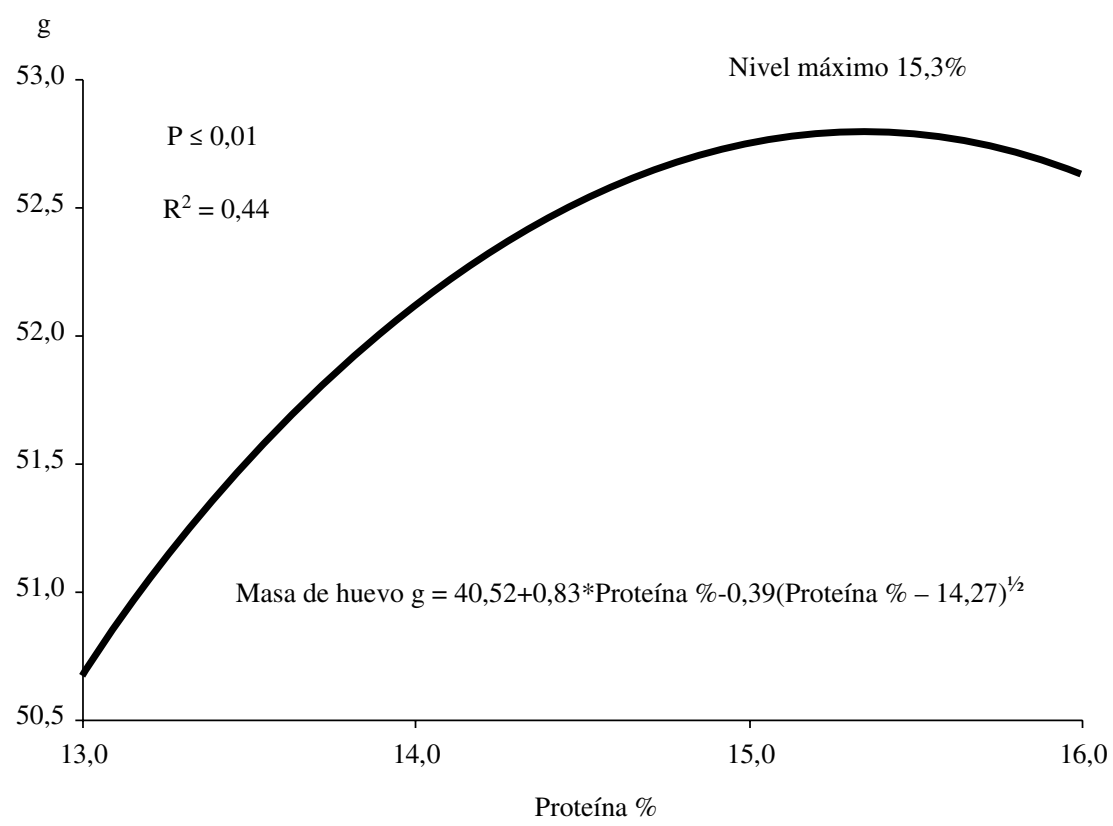

Figura 3. Respuesta de la masa de huevo ave día en gallinas con diferentes niveles de proteína.

Performance of egg mass per day in laying hen fed with different protein levels.

con el consumo de proteína, $\%$ de postura $Y=76,8+0,85^{*}$ proteína $-0,50$ (proteína - 14,27) $)^{1 / 2} R^{2}=0,33(P \leq 0,05)$; para una máxima producción se requiere un consumo de proteína de $15,1 \mathrm{~g}$ ave $\mathrm{e}^{-1} \mathrm{~d}^{-1}$ (figura 1), para peso del huevo $\mathrm{Y}=53,5+0,37 *$ proteína $-0,12 *$ (proteína $-14,27)^{1 / 2} \mathrm{R}^{2}$ $=0,33(\mathrm{P} \leq 0,05)$, para un máximo se requiere de un consumo de proteína de $15,8 \mathrm{~g} \mathrm{ave}^{-1} \mathrm{~d}^{-1}$ (figura 2). Para masa de huevo ave $\mathrm{d}^{-1}$ que es una variable que combina el porcentaje de postura y el peso promedio del huevo $\mathrm{g}, \mathrm{Y}=40,5+0,83^{*}$ proteína $-0,39 *(\text { proteína }-14,27)^{1 / 2} \mathrm{R}^{2}=0,44(\mathrm{P} \leq 0,01)$, para un máximo se requiere de un consumo de $15,3 \mathrm{~g}$ por ave $\mathrm{d}^{-1}$ (figura 3) y conversión alimentaria $\mathrm{Y}=2,333-0,030^{*}$ proteína $+0,005^{*}$ (proteína $\left.-14,27\right)^{1 / 2} \mathrm{R}^{2}=0,46(\mathrm{P} \leq 0,01)$ no se encontró un nivel máximo, sino un nivel para obtener la mínima o mejor conversión alimentaria y fue de 17,2\%; sin embargo, este nivel está fuera de la zona de exploración (figura 4), para consumo de alimento, no hubo respuesta a la regresión polinomial $(\mathrm{P}>0,05)$. 


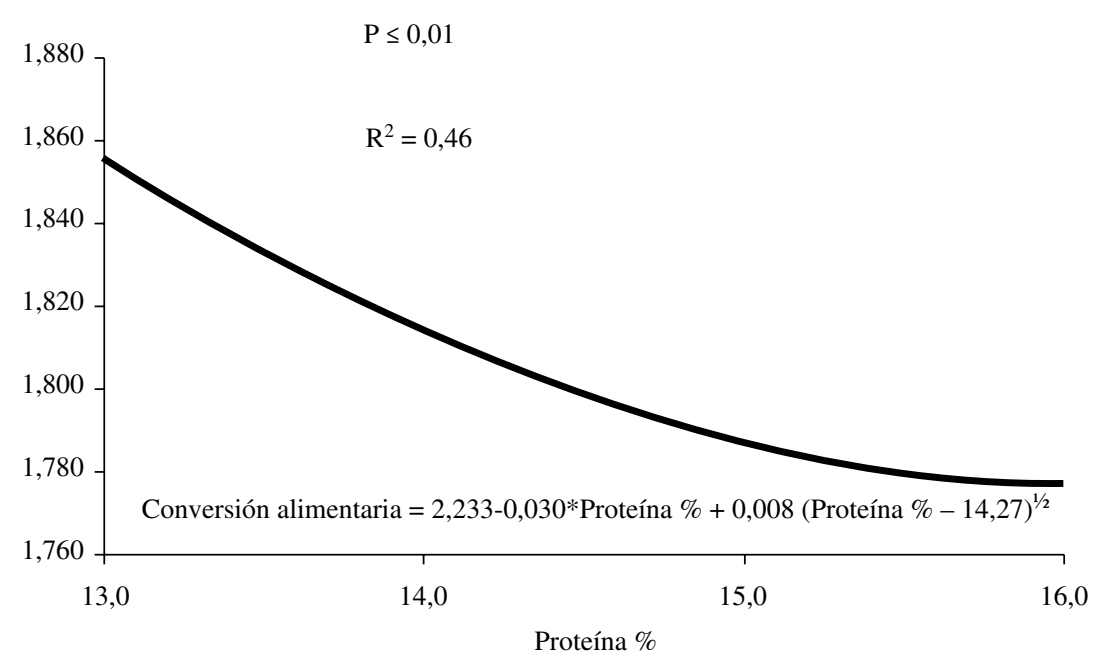

Figura 4. Respuesta a la conversión alimenticia en gallinas con diferentes niveles de proteína.

Response in feed conversion laying hens with different protein levels.

\section{DISCUSIÓN}

Es posible que la inadecuada relación de la arginina y la valina con la lisina, en las dietas con 13 y $14 \%$ PC (para arginina: 92,8 y $103,6 \%$ y para valina 78,7 y $84,9 \%$ ) fuera un factor limitante para una mayor producción. El NRC (1994) sugiere una relación de lisina:arginina de $101 \%$. Santiago (2011) menciona una relación de $100 \%$ y Bregendahl y col $(2008)^{1}$ tuvieron $107 \%$ para la relación lisina y arginina, Coon y Zhang (1998) señalan una relación de $130 \%$ y Coon en 2005 redujo esta relación en $120 \%$. En las dietas con 15 y $16 \%$ la relación fue de 114,4 y $125,1 \%$ respectivamente. La literatura menciona una gran variación en la relación valina:lisina, siendo desde $89 \%$ hasta $102 \%$ (Leeson y Summers 2001, Coon 2005); Santiago (2011) sugiere una relación con respecto de la lisina de 95\%; Bregendahl y col de 93\%, el valor encontrado en este trabajo estuvo cercano a lo reportado por estos autores.

Por otro lado, Kidd y Hackenhaar (2005) señalan que no existe ningún tipo de combinación de insumos que pueda evitar que la arginina sea el cuarto aminoácido limitante en dietas basadas principalmente en sorgo como fuente de grano en pollo de engorda. Por lo cual este aminoácido se ha formulado a un nivel adecuado es por la implementación de un nivel mínimo de proteína cruda en la dieta por lo que las dietas de gallina de postura se formulan a niveles alrededor de $18 \%$ de PC.

1 Bregendahl K, S Roberts, B Kerr, D. Hoehler. 2008. Ideal amino acid profile for 28-to-34-week-old laying hens. Iowa State University Animal Industry Report 2008.http://www.ans.iastate.edu/report/ air/2008pdf/R2332.pdf. (consulta mayo 2010).
El valor encontrado para una máxima producción, el cual está alrededor de 15\% de proteína cruda, es inferior al encontrado por Leeson y Summers (2001) quienes mencionan un nivel de $17 \%$ de proteína cruda en dietas tipo práctica con margen de seguridad, y el manual Hy-Line W36 (2011) que menciona un nivel de 16\% de proteína cruda; los valores de consumo de aminoácidos encontrados en este trabajo fueron en promedio 7,6\% menores a lo que menciona el manual Hy-Line W36 (2011) y 9,8\% a lo que menciona Santiago (2011). En este trabajo se muestra que es posible disminuir los niveles de proteína cruda siempre y cuando se cubran los requerimientos de los aminoácidos esenciales ya que los valores productivos obtenidos estuvieron de acuerdo a lo señalado por el manual de la estirpe Hy-Line W36 (2011) .

D'Mello y Lewis (1970) mencionan que existió disminución del consumo de alimento en pollos de engorda al ser alimentados con dietas deficientes en arginina, efecto que no fue observado en ninguno de los niveles de proteína probados en este trabajo, por lo que probablemente el consumo de alimento no se afecte como en el pollo de engorda por el consumo limitado de arginina; sin embargo, en el caso de las gallinas probablemente la carencia marginal en este estudio de arginina o valina fue compensada con un mayor consumo de alimento, ya que se ha demostrado (D'Mello 1994) que los aminoácidos pueden regular el consumo de alimento estimulando el centro del apetito.

De los resultados obtenidos bajo las condiciones experimentales empleadas se puede concluir que el comportamiento productivo en gallinas Hy-Line W36 fue menor en dietas sorgo + soya con un perfil de proteína ideal con $13 \%$ de proteína cruda. Para máxima masa de huevo $a^{-1} \mathrm{~d}^{-1}$ se requiere un nivel de 15,3\% PC. La relación lisina-arginina y lisina-valina aparentan ser limitantes para dietas con $13 \%$ de proteína. 


\section{RESUMEN}

Existe poca información del uso de dietas reducidas en proteína con perfil de proteína ideal para gallina, por esto se llevó a cabo un experimento para evaluar el comportamiento productivo de gallinas con dietas bajas en proteína con perfil de proteína ideal. Se usaron 240 gallinas Hy-Line W36 de 26 a 44 semanas de edad, los tratamientos se distribuyeron entre las unidades experimentales en cuatro tratamientos con cinco réplicas de 12 aves cada una. El diseño experimental fue completamente al azar. Las gallinas se alimentaron con dietas sorgo + pasta de soya y aminoácidos sintéticos formuladas a 13,14, 15 y $16 \%$ de proteína con niveles similares de los aminoácidos digestibles lisina $0,725 \%$ (100), metionina + cistina $0,596 \%$ (82), treonina $0,509 \%$ (70) y triptófano $0,179 \%$ (25). Las variables estudiadas fueron consumo de alimento, porcentaje de postura, peso del huevo, masa de huevo por ave $\mathrm{d}^{-1}$ y conversión alimentaria. Se realizó un análisis de observaciones repetidas y un análisis de regresión con transformación cuadrática con cada nivel de proteína. Además, mediante la derivada de la fórmula de regresión se calculó el valor de la proteína que maximice la producción. Hubo un efecto cuadrático $(\mathrm{P} \leq 0,05)$ para porcentaje de postura, peso del huevo, masa de huevo ave $\mathrm{d}^{-1} \mathrm{y}$ consumo de alimento. El análisis de los datos sugiere que para una mejor masa de huevo ave $\mathrm{d}^{-1}$ de gallinas Hy-Line W36, 15,3\% es la proteína requerida en la dieta con los principales aminoácidos sintéticos presentes en el mercado. La relación lisina-arginina aparenta ser limitante para dietas con $13 \%$ de proteína así como la relación de lisina-valina.

\section{REFERENCIAS}

AOAC, Association of Official Analytical Chemists. 2002. Official Methods of Analysis. Vol 1. $17^{\text {th }}$ ed. Association of Official Analytical Chemists, Washington, DC, USA.

Reeves III JB. 2000. Use of near infrared reflectance spectroscopy. In D'Mello JPF (ed). Farm animal metabolism and nutrition. CAB international, London, UK, Pp 185-208.

Baker DH, TK Chung. 1992. Ideal protein for swine and poultry. Fermex Technical review-4. Nutria-Quest Inc., Chesterfield, MO, USA.

Bray DJ. 1964. Studies with corn-soya laying diets. 7. Limiting amino acids in a 60:40 blend of corn and soybean protein. Poult Sci 43 , 396-401.

Calderon VM, LS Jensen. 1990. The requirement for sulfur amino acid by laying hens as influenced by the protein concentration. Poult Sci 69, 934-944.

Coon C. 2005. Requerimientos y perfil ideal de aminoácidos en ponedoras comerciales. XII Congreso Bienal AMENA, Puerto Vallarta, Jal, México.

Coon C, B Zhang. 1998. Ideal amino acid profile and metabolizable energy requirements for layers. $59^{\text {th }}$ Minnesota Nutrition Conference \& IPC technical Symposium, University of Minnesota Extension Service, Bloomington, Minnesota, USA, Pp 263-278.
Cuca GM, Avila GE, Pro MA. 2008. Alimentación de las aves. $2^{\mathrm{a}}$ ed. Universidad Autónoma de Chapingo, Estado de México, México.

Denis GZ. 1987. Cálculo en geometría analítica. Ed. Iberoamericana, México, D.F.

D’Mello JPF, D Lewis. 1970. Amino acid interactions in chick nutrition. 1. The interrelationship between lisine and arginine. Br Poult Science 11, 299-311.

D'Mello JPF. 1994. Amino acid imbalances, antagonisms and toxicities. In: D'Mello JPF (ed). Amino acids in farm animal nutrition. $1^{\text {st }} \mathrm{ed}$. CAB International, Wallingford, UK, Pp 63-97.

Fuente MB, CA Díaz, LJ Lecumberri, GE Avila. 2005. Necesidades de lisina y aminoácidos azufrados digestibles en gallinas Leghorn Blanca. Vet Mex 2, 135-146.

Harms RH, GB Russell. 1993. Optimizing egg mass with amino acid supplementation of a low-protein diet. Poult Sci 72, 1892-1896.

Hy-line variedad W-36. 2009-2011. Guía de manejo comercial. Iowa, USA.

Johnson D, H Fisher. 1958. The amino acid requirement of laying hens. 3. Minimal requirement levels of essential amino acids; techniques and development of diet. Br J Nutr 12, 276-285.

Keshavarz K, ME Jackson. 1992. Performance of growing pullets and laying hens fed low-protein, amino acid-supplemented diets. Poult Sci 71, 905-918.

Keshavarz K, NM Dale, HL Fuller. 1980. The use of non-protein nitrogen compounds, sugar beet molasses and their combinations in growing chicks and laying rations. Poult Sci 59, 2492-2499.

Kidd MT, L Hackenhaar. 2005. Dietary threonine for broilers: dietary interactions and feed additive supplement use. CAB Reviews. 1: $\mathrm{N}^{\circ} 005$.

Leeson S, Summers JD. 2001. Scott's Nutrition of the chicken. $4^{\text {th }}$ ed. University Books, Guelph, Ontario, Canada.

Morris TR, RM Gous. 1988. Partitioning of the response to protein between egg number and egg weight. Br Poult Sci 29, 93-99.

National Research Council. 1994. Nutrient Requirements of Poultry. $9^{\text {th }}$ ed. National Academic Press, Washington, DC, USA.

Penz AM Jr, LS Jensen. 1991. Influence of protein concentration, amino acid supplementation and daily time of access to high or low-protein diets on egg weight and components in laying hens. Poult Sci 70, 2460-2466.

Roland D Sr. 1980. Egg shell quality. II. Effect of dietary manipulations of protein, amino acids, energy and calcium in young hens on egg weight, shell weight, shell quality and egg production. Poult Sci 59, 2047-2054.

Santiago RH. 2011. Tablas brasileñas para aves y cerdos, Composición de alimentos y requerimientos nutricionales. $3^{\mathrm{a}} \mathrm{ed}$. Universidad Federal de Vicosa, Vicosa, Brasil.

SPSS Inc. 1989-1997. SPSS for Windows (computer program) Version 8.0.0 spssinc.

Summers JD, JL Atkinson, D Spratt. 1991. Supplementation of a low protein diet in an attempt to optimize egg mass output. Can J Ani Sci 71, 211-220. 